\title{
The continuous analysis of nitrate and ammonium in aerosols by the steam jet aerosol collector (SJAC): extension and validation of the methodology
}

\author{
J. Slanina ${ }^{\mathrm{a}, *}$, H.M. ten Brink ${ }^{\mathrm{a}}$, R.P. Otjes ${ }^{\mathrm{a}}$, A. Even ${ }^{\mathrm{a}}$, P. Jongejan ${ }^{\mathrm{a}}$, A. Khlystov ${ }^{\mathrm{a}}$, \\ A. Waijers-Ijpelaan ${ }^{\mathrm{a}}, \mathrm{M} . \mathrm{Hu}^{\mathrm{b}}, \mathrm{Y} . \mathrm{Lu}^{\mathrm{c}}$ \\ ${ }^{a}$ Netherlands Energy Research Foundation (ECN), P.O. Box 1, 1755 ZG, Petten, The Netherlands \\ ${ }^{\mathrm{b}}$ Center of Environmental Sciences, Peking University, Beijing 100871, China \\ ${ }^{\mathrm{c}}$ Food Science Buildings, Iowa State University, Ames, Iowa, IA 50011, USA
}

Received 19 July 2000; received in revised form 20 November 2000; accepted 30 November 2000

\begin{abstract}
Classical methodology based on the application of filters for sampling, followed by extraction and analysis, introduces severe artifacts for semi-volatile compounds like ammonium nitrate. These filter methods do not meet the requirements for the assessment of the impact of aerosols on acidification, air quality and especially on the radiative balance, in terms of required speed, detection limits and selectivity. These artifacts are avoided by using a steam jet aerosol collector sampler, based on scavenging of aerosols by droplet formation, in combination with on-line analytical techniques such as ion-chromatography for nitrate and membrane separation followed by conductivity detection for ammonium. The SJAC sampler combines very low blanks with high efficiency of collection of particles. The ammonium detector and the IC system, based on 1-point internal standard calibration in combination with correction for curved calibration graphs, enables detection of ammonium and nitrate at background conditions, the detection limit is about $0.02 \mu \mathrm{g} \mathrm{m}^{-3} \mathrm{of}$ ammonium and nitrate. Accuracy is, depending on ambient concentration, in the order of 5-10\% relative, at a range of $0.05-50 \mu \mathrm{g} \mathrm{m}^{-3}$. The time resolution is $15-120 \mathrm{~min}$, depending on required detection limit, and is short enough for continuously monitoring the chemical composition of aerosols. Quality assurance and quality control experiments and intercomparison experiments with classical filter methods, thermo-denuder systems, denuder difference methods and other continuous monitoring techniques have shown that the results are reliable. The instrument has successfully been employed in field campaigns in Europe and the US. C) 2001 Elsevier Science Ltd. All rights reserved.
\end{abstract}

Keywords: Aerosol; Chemical analysis; Nitrate; Ammonium; On-line

\section{The problem, general background}

Little attention has been given in the last decade for the methodologies for analysis of chemical composition of aerosols. Routine filter methods were used to obtain an overview of the chemical composition of aerosols. New instruments, like monitors based on mass spectrometry for chemical characterization of aerosols and

\footnotetext{
* Corresponding author.

E-mail address: slanina@ecn.nl (J. Slanina).
}

specific methodology to investigate carbon content in the aerosols were generally dedicated to very specific subjects like the composition of stratospheric aerosol or "soot" monitoring. This situation has drastically changed, as the chemical analysis of semi-volatile species like ammonium nitrate in aerosol particles is necessary to shed light on a number of important issues such as the effects of aerosols on human health, the impact of aerosols on the radiative balance of the earth and the role of aerosols in visibility problems (Charlson et al., 1992; IPCC, 1998).

At present, sampling methods which allow comprehensive analysis of aerosols, with the necessary time 
resolution of $1-3 \mathrm{~h}$ as needed for studying the impact on health or the radiative balance do not exist. The generally applied filter based methods need sampling times of 5-24 h, they lead to underestimation of volatile components, suffer from artifacts caused by topological reactions, are plagued by high and variable blanks and last but not least, are labor intensive.

The classical methods used for sampling of aerosols, based on the use of filters or filter packs, can lead to artifacts such as loss of semi-volatile components. This has been known for a long time and has been documented in detail in the literature (Chow, 1995; Keuken, 1989; Niessner and Klockow, 1980; Slanina et al., 1992).

These artifacts are caused by topological reactions, reactions of different species, on the surface of the sampling filter, or by evaporation of compounds such as ammonium nitrate.

The main topological reactions leading to losses of nitrates are the reactions of nitrate with sulfuric acid, or ammonium hydrogen sulfate with ammonium nitrate, leading to the formation and loss of nitric acid.

The losses by the evaporation of ammonium nitrate are also well documented in earlier as well as very recent literature, as the implications for health studies and on the radiative forcing of aerosols are now generally perceived as important (Bergin et al., 1997; Herring and Cass, 1999).

The conclusions of the investigations into these artifacts have led to the following general conclusions:

- As long as the sampled gases and aerosols are in equilibrium with each other and with the aerosols already sampled on the filter, artifacts are generally avoided. This means that if sampling periods are very short, a few hours or less, the results are much better compared to those obtained with long sampling periods ( $24 \mathrm{~h}$ or more).

- High loading of the filter increases the possibility of topological reactions and hence, e.g., losses of nitrate and chloride after conversion to nitric acid and hydrochloric acid.

- Some filter materials, such as cellulose acetate and cellulose matrix filters, retain nitric acid quantitatively and ammonia too, at least if the concentration is not too high.

For many areas of investigations, e.g. the radiative forcing of aerosols, it is necessary to measure aerosol composition with a reasonable time resolution.

Errors by contamination become problematic especially at low ambient concentrations and short sampling periods. In order to avoid these errors, the tendency to sample for longer duration and to obtain higher loadings on the filters exists.
Denuder difference techniques have been always plagued with this blank problem. Denuders have been used to scavenge nitric acid, and filters and/or filterpacks have been used to sample nitrate. The combination of denuders, to strip nitric acid and ammonia from the sampled air, and a filterpack (consisting of e.g. Teflon filter and a phosphoric impregnated filter to scavenge ammonia due to evaporation of ammonium nitrate and a sodium fluoride impregnated filter to retain the liberated nitric acid) will in principle result in correct data, regarding the speciation of nitric acid and nitrate. But the blank problems, as well as the total amount of work to be done indeed inhibit the application of this method on a wide scale.

In short, with the standard filter methods researchers are caught between two evils, blanks and sampling artifacts. In most cases, people have preferred higher sampling loadings. This approach leads to unpredictable underestimation of nitrate and ammonium (Keuken, 1989). In Figs. 1 and 2 an intercomparison of sampling of ambient aerosol by a Teflon filter and with a thermodenuder (as explained later) is given. The measurements were performed under relatively good circumstances for filter measurements: The sampling period was about $3 \mathrm{~h}$ only and the load on the filters was quite low, compared with, e.g., high-volume sampling methods. The filter consisted of a Teflon filter (Millipore LS $5 \mu \mathrm{m}$ ) first, to capture ammonium nitrate and a $\mathrm{NaF}$-impregnated filter to scavenge nitric acid plus a phosphoric acid-impregnated filter to retain ammonia.

Losses of nitrate were observed on the first Teflon filter. The losses of ammonium were less striking, partially because ammonium concentrations in The Netherlands are relatively high. The losses in nitrate have a peculiar character but are very often in the order of $50 \%$ or higher. This is also reflected when nitric acid measurements between filterpacks and denuders are compared. In the filterpack, the first filter retains the particulate nitrate, the second filter samples nitric acid which either was present in the ambient air or has been liberated at the first filter due to topological reactions or evaporation of ammonium nitrate.

The intercomparison between results obtained by denuders and filterpacks in Fig. 1 makes it clear that the filterpack measures much higher nitric acid concentrations, caused by artifact evaporation of ammonium nitrate from the first (Teflon) filter. Blanks are a very difficult problem indeed. In order to obtain the results as given in Figs. 1 and 2, a special laboratory where no other, possibly interfering, activities were allowed, was used and the actual filter extractions were carried out in a laminar flow cabinet.

Even then, the detection limits for ambient nitrate are in the order of $0.2-0.5 \mu \mathrm{g} \mathrm{m}^{-3}$ nitrate for a sample of $1 \mathrm{~m}^{3}$ of air or more. The total amount of labor to prepare a denuder filter pack combination for a "denuder 


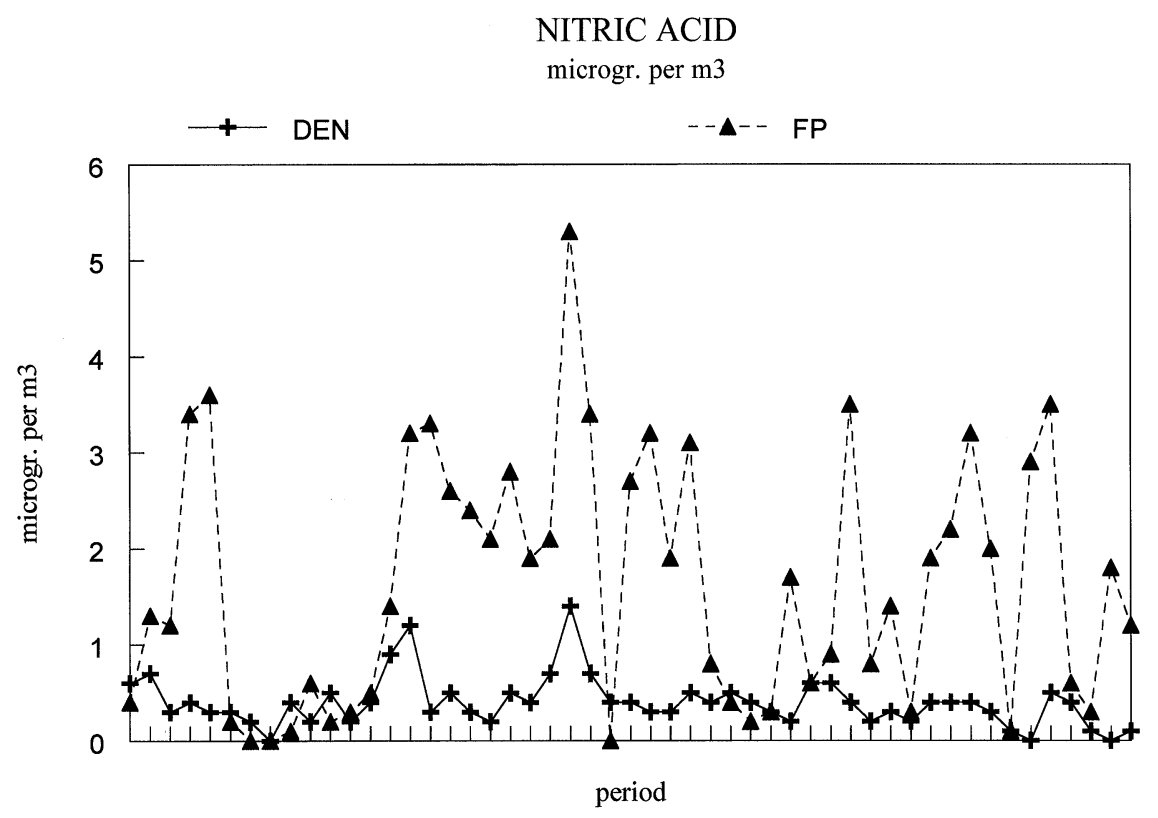

Fig. 1. Intercomparison between filter pack (second filter, coated with NaF) and denuder for nitric acid.

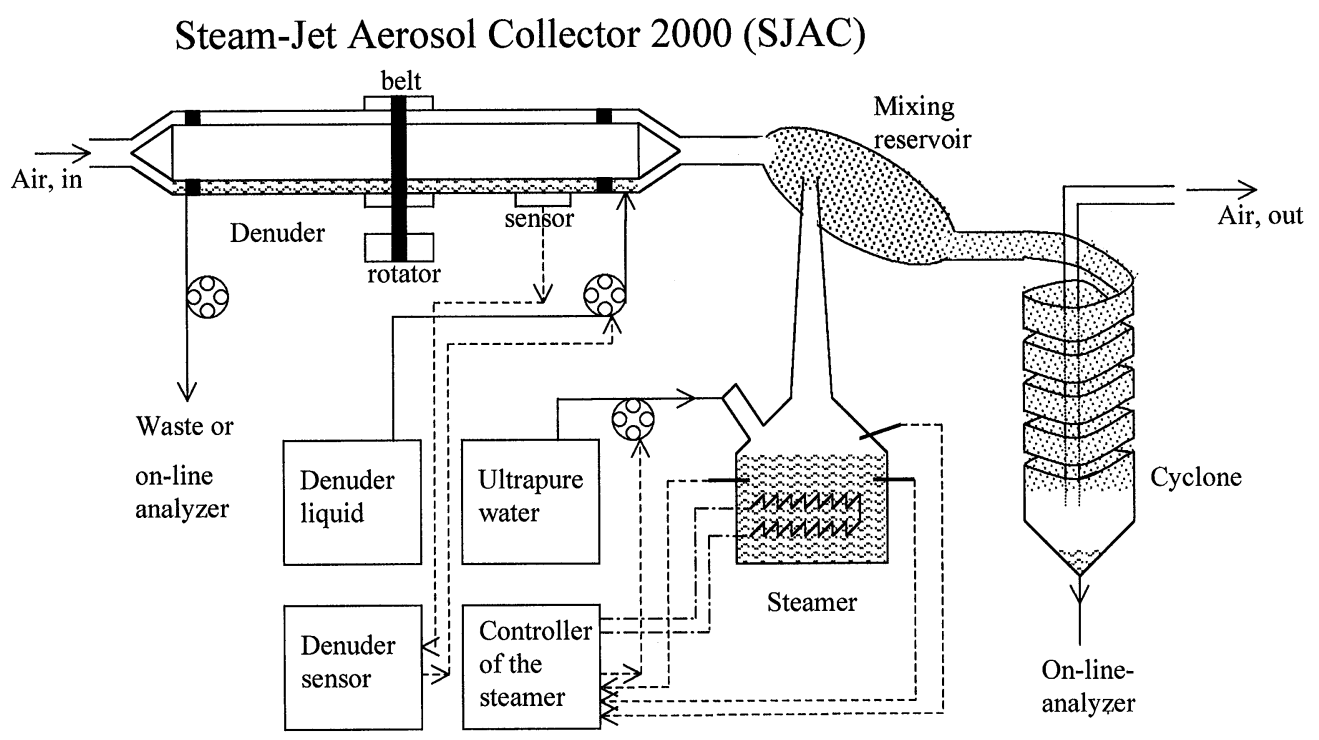

Explanation

(drawing not to scale)

liquid, droplets

69 liquid pump, $\quad$ spacer

$\longrightarrow$ liquid,.$---\rightarrow$ signal,.$--\rightarrow$ power.

Fig. 2. Overview of SJAC Sampler. 
difference" measurement, even with the application of some time-saving steps is in the order of 2-3 man hours per measurement. The increased demand for chemical speciation of aerosol, including semi-volatile species like ammonium nitrate, together with the high blanks and the labor tied in with denuder-filter pack techniques has prompted the research for better methodologies. One answer has been the development of the steam-jet aerosol collector (SJAC) (Wyers et al., 1992; Khlystov et al., 1995) to sample efficient aerosol with very low blanks. Other developments have been described e.g. by Dasgupta and Baltensberger (Simon and Dasgupta, 1995; Zellweger et al., 1999), using basically the same approach adding steam to sampled air and generating condensation droplets. This apparatus employs a lesser sample volume, $5-101 \mathrm{~min}^{-1}$, which was chosen as this apparatus was not developed for sampling of very polar gaseous compounds. If these compounds and not only aerosols are sampled, problems due to inlet losses of these gases will occur.

\section{SJAC methodology for sampling ambient aerosol}

\subsection{The SJAC sampler}

A general scheme of the SJAC (Khlystov et al., 1995) is given in Fig. 2. A wet denuder system is used to scavenge interfering gaseous nitrogen compounds, in this case ammonia and nitric and nitrous acid. The absorption solution is a $10^{-5} \mathrm{M}$ carbonate solution, which effectively retains all gaseous interferences such as $\mathrm{HNO}_{3}, \mathrm{HNO}_{2}$, $\mathrm{SO}_{2}$ and $\mathrm{NH}_{3}$. This air stream is rapidly mixed with steam inside the mixing reservoir. The resulting high supersaturation causes aerosol particles to grow rapidly (within $0.1 \mathrm{~s}$ ) into droplets of at least $2 \mu \mathrm{m}$ diameter. These droplets containing dissolved aerosol species are then collected by a cyclone with a cut-off of $2 \mu \mathrm{m}$. The solution collected in the cyclone is constantly pumped out with a peristaltic pump and can be analyzed on- or off-line.

Air is drawn into the system by a pump equipped with a critical orifice. The mass sampling efficiency of the instrument was found to be at least $99 \%$. In fact, counting particles at the inlet and outlet of the SJAC indicates that the efficiency is at least $99.9 \%$ for particles over $10 \mathrm{~nm}$. Not only water-soluble aerosol is sampled but the same sampling efficiency is also found for insoluble material such as carbon black. The system can easily be coupled with an array of detection systems, such as IC, and ammonium detection based on conductivity and has a time resolution in the order of 15-120 min, depending on the concentration levels analyzed.

Important parameters such as the sample flow, volume of the condensation vessel, thermal isolation of the vessel, efficiency depending on sample flow and amount of steam injection, and design of the cyclone were systematically studied in order to optimize the apparatus. The conclusion, quite surprising, was that the apparatus functions rather well regardless of the variations of these parameters. The sample flow in these applications was chosen at a level of $201 \mathrm{~min}^{-1}$ but the maximum sample flow for sampling $99 \%$ of the particles over $10 \mathrm{~nm}$ is $601 \mathrm{~min}^{-1}$. The volume of the condensation vessel is not critical either, and isolation does not influence sampling efficiency. Isolation of the actual condensation chamber of the SJAC has been investigated but did not influence the efficiency of aerosol collection. The optimal conditions for sampling are obtained at a sampling flow of ca. $20-301 \mathrm{~min}^{-1}$, using $2.5 \mathrm{~g}$ steam. About $0.4 \mathrm{ml}$ condensed water which leaves the cyclone is used for the analysis, the rest of the water is found back in the condenser and as vapor pumped off by the sampling pump. The detection limit of the sampler for ammonium, sulfate, nitrate and chloride ions is between 20 and $50 \mathrm{ng} \mathrm{m}^{-3}$ depending on the sampling time. The blank of the SJAC is equivalent to $0.02 \mu \mathrm{g}$ ammonium nitrate or less, calculated on the basis of a $30 \mathrm{~min}$ sampling period.

The sample stream after the cyclone is first led through a de bubbler to get rid of air bubbles and the sample stream of the SJAC (and of the denuder system if one analyzes aerosols plus gases) is either switched to the ammonium detector or to the IC. While the first sample is analyzed for ammonium and nitrate, the sampling systems are filled with the next sample and then the cycle is repeated. A time resolution of $15 \mathrm{~min}$ can be reached. The flow rates of solutions to the ammonium detector, the IC and the total flow leaving the denuder and the SJAC are monitored, as variations in these flows directly influence the results.

\subsection{On-line detection of ammonium and nitrate}

The ammonia/ammonium detection is based on addition of $\mathrm{OH}^{-}$ions, converting all ammonium to $\mathrm{NH}_{3}$, as developed by Carlson (Carlson et al., 1990); this $\mathrm{NH}_{3}$ can pass through a Teflon membrane and is taken up in very pure water. Detection then follows based on conductometry (Wyers et al., 1993; Slanina and Wyers, 1994). A schematic diagram of the detector is given in Fig. 3. The sample stream is mixed in a ratio of about $10: 1$ with a $0.5 \mathrm{M}$ sodium hydroxide solution so that the $\mathrm{pH}$ of the solution is about 12.3 or higher. Under these conditions, all ammonium is converted to $\mathrm{NH}_{3}$. The membrane is a Schleicher and Schull Teflon filter with holes of $0.2 \mu \mathrm{m}$. About $30 \%$ of the ammonium in the sample solution passes the membrane and is taken up by a water stream

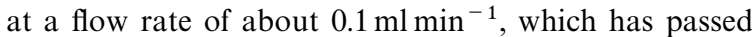
through a mixed-bed exchanger and hence has a very low conductivity. The detection of the ammonium in this water stream is carried out by conductometry. The temperature of the stream is measured by a thermistor to 


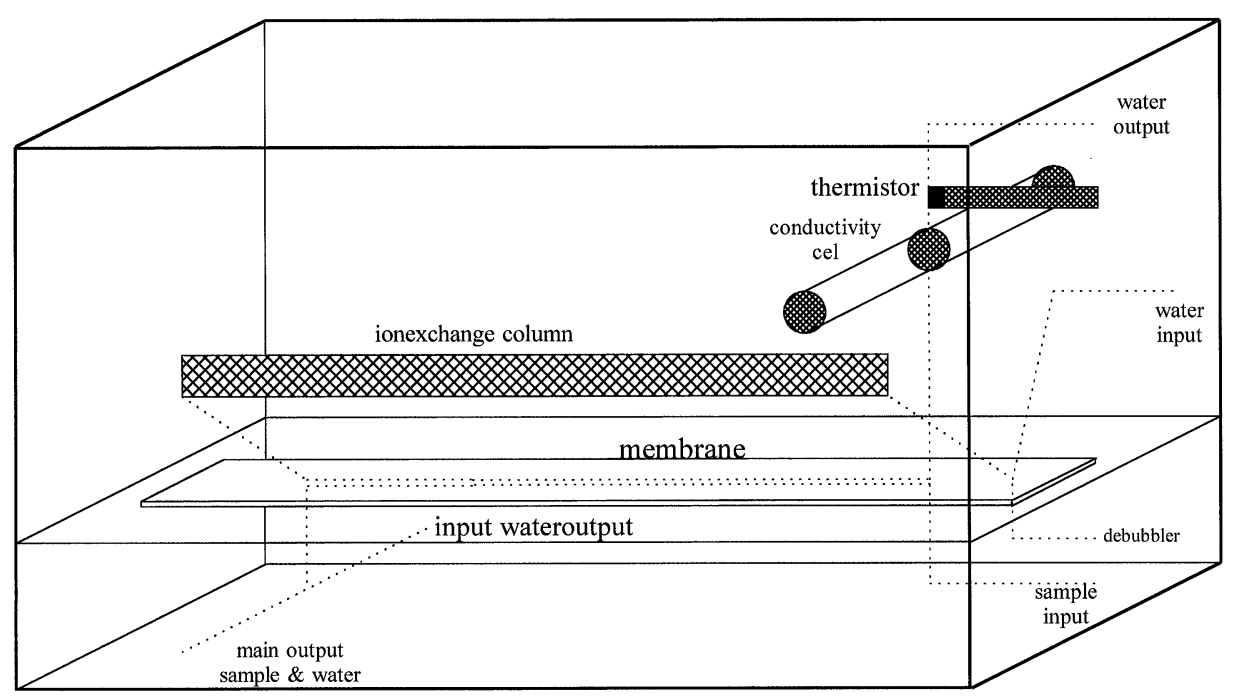

Fig. 3. Overview of ammonia/ammonium detection.

correct for temperature effects (about $2 \%{ }^{\circ} \mathrm{C}^{-1}$ ). At low concentration of ammonia the calibration graph is not linear because the $\mathrm{OH}$-ions generated by the uptake of ammonia influence the water equilibrium. $\mathrm{H}^{+}$ions have a higher conductivity than ammonium or $\mathrm{OH}$ ions leading to curved calibrations. This problem can be avoided by adding $50-60 \mu \mathrm{gl}^{-1}$ of ammonium to the sodium hydroxide solution, which is added to the sample solution. This induces a background of about $2 \times 10^{-6} \mathrm{M}$ ammonium and hence the same concentration of $\mathrm{OH}^{-}$. This extra $\mathrm{OH}^{-}$reduces the $\mathrm{H}^{-}$due to the water equilibrium to sufficient low values to obtain straight calibration graphs.

The transfer of ammonium through the filter is very reproducible, even though only a limited fraction of about $30 \%$ is transferred to the solution where the conductivity measurement is performed. A calibration by way of one or two standards, containing typically between 50 and $500 \mu \mathrm{g} \mathrm{NH} \mathrm{NH}^{+} 1^{-1}$ is performed once a week. The variation coefficient of the ammonium detector is 0.4 $\%$ relative at a concentration of $100 \mu \mathrm{g} 1^{-1}$ or higher. The detection limit is about $500 \mathrm{ng}^{-1}$ in the watery phase (10-20 $\mathrm{ng} \mathrm{m}^{-3}$ in air). The detector has proven to be very accurate, quite sturdy and reliable and needing infrequent calibrations, typically once a week.

The IC system has also been described earlier (Oms et al., 1996), and is given in Fig. 4. The IC system employs two sampling concentrator columns. While one column is loaded by the ions in the water stream of the SJAC or the denuder system, the other is switched into the IC system and is stripped by the eluant (a mixture of $3 \times 10^{-3}$ sodium carbonate and $1.3 \times 10^{-3} \mathrm{M}$ sodium bicarbonate). A Dionex column and a Dionex membrane suppressor is employed. A warning is due here: Mem- brane seperators induce, be it low, sulfate blanks and the blank of the system must be checked from time to time. Conductivity detection is performed by means of a Dionex conductivity detector. Calibration was earlier performed by way of five standards as the calibration graph is not linear at low concentrations, see below, but this calibration procedure is quite time consuming and has to be performed regularly.

A solution for the curved calibration graph, is the correction for the non-linearity of conductometric detection in IC. In the suppressor all cations are converted to $\mathrm{H}^{+}$and the signal detected is hence the sum of the conductivity of the ion of interest plus the conductivity of $\mathrm{H}^{+}$. The eluant is converted to $\mathrm{H}_{2} \mathrm{CO}_{3}$ or a solution of $\mathrm{CO}_{2}$ in water by the suppressor. The background signal is caused by the dissociation of $\mathrm{H}_{2} \mathrm{CO}_{3}$ :

$$
\mathrm{H}_{2} \mathrm{CO}_{3} \leftrightarrow \mathrm{H}^{+}+\mathrm{HCO}_{3}^{-}
$$

Both the $\mathrm{H}^{+}$ions and the $\mathrm{HCO}_{3}^{-}$ions contribute to this background conductivity. The $\mathrm{H}^{+}$generated in the suppressor will shift this equilibrium to the right, lowering the contribution of the background conductivity. This shift results in a non-linearity of the conductivity signal until all $\mathrm{HCO}_{3}^{-}$is converted to $\mathrm{CO}_{2}$. Under the standard conditions, $3 \mathrm{mmol}$ carbonate plus bicarbonate eluant, based on the $\mathrm{p} K_{1}$ of 6.37 for carbonic acid, the $\mathrm{H}^{+}$and the bicarbonate concentrations will be in the order of $4 \times 10^{-5}$ so a maximum non-linearity is expected and found in the concentrations below $0.1 \mathrm{mmoll}^{-1}$ or in the range between 0 and $5 \mu \mathrm{gl}^{-1}$ of nitrate. The non-linearity as function of the sample concentration is given in Fig. 5.

If the cell factor of the detector is known or measured, the specific conductivity of the ions of interest and the 


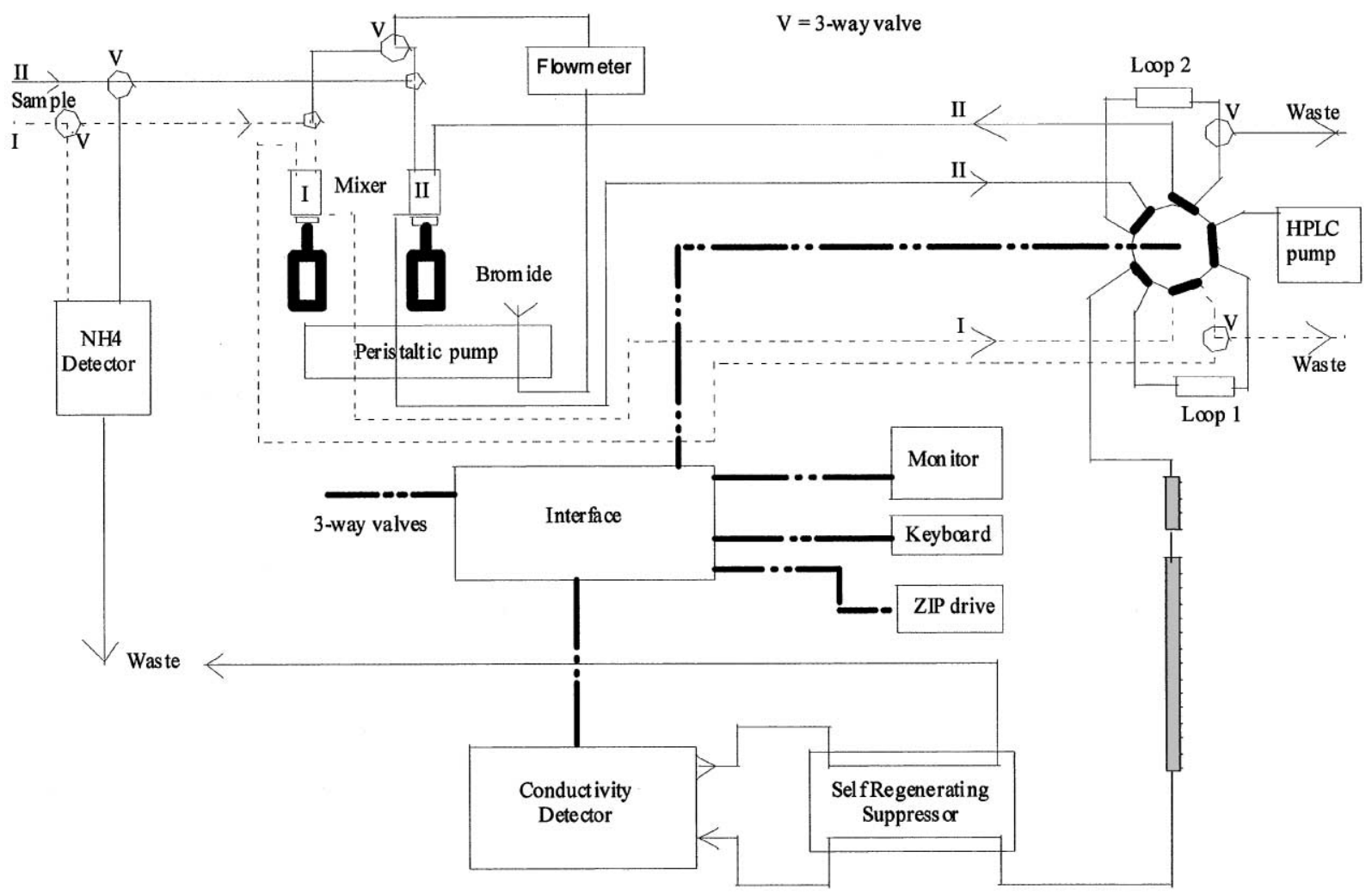

Mobile IC - Analysis of denuder and aerosol sample, direct injection

Fig. 4. Overview of IC system.

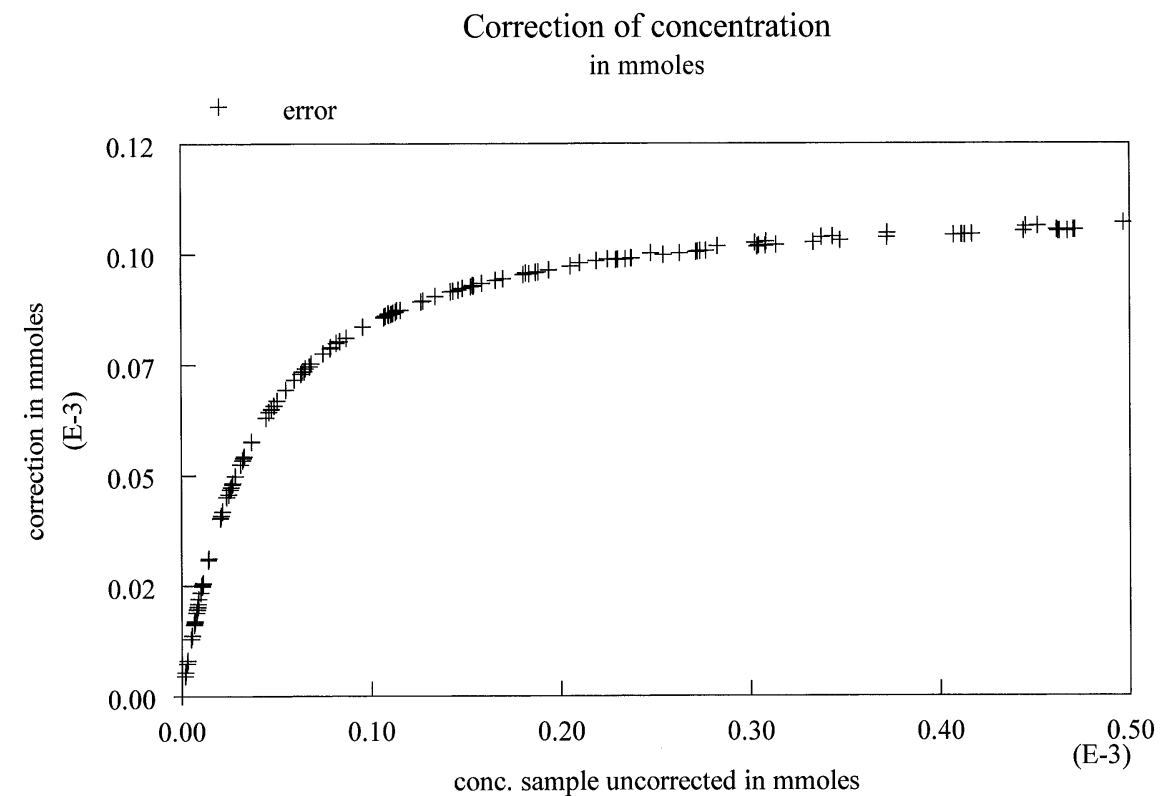

Fig. 5. Non-linearity detector response of IC system as a function of analyte concentration in sample. 
relevant acid dissociation constants are known, the correction can easily be calculated. A description of the correction formula is given elsewhere (Os et al., 1984):

The balance of the total conductivity plus mass and charge results in a square root equation

$A c_{x^{-}}^{2}+B c_{x^{-}}+C=0$

then yields a corrected analyte concentrations as

$c_{x^{-}}=-B-\left(B^{2}-4 A C\right)^{1 / 2} / 2 A$,

where

$$
\begin{aligned}
\mathrm{A}= & \left(\Lambda_{\mathrm{H}^{+}}+\Lambda_{x^{-}}\right)\left(\Lambda_{x^{-}}-\Lambda_{\mathrm{HB}^{-}}\right), \\
B= & -0.5\left(2 \Lambda_{x^{-}}+\Lambda_{\mathrm{H}^{+}}-\Lambda_{\mathrm{HB}^{-}}\right)\left(\Lambda_{\mathrm{H}^{+}}+\Lambda_{\mathrm{HB}^{-}}\right) \\
& \times\left(K_{\mathrm{a} 1}^{2}+4 c_{\mathrm{E}} K_{\mathrm{a} 1}\right)^{1 / 2}-S_{\mathrm{N}} P\left(2 \Lambda_{x^{-}}+\Lambda_{\mathrm{H}^{+}}-\Lambda_{\mathrm{HB}^{-}}\right) \\
& -0.5 K_{\mathrm{a} 1}\left(\Lambda_{\mathrm{H}^{+}}+\Lambda_{\mathrm{HB}^{-}}\right)^{2}(1-2 \gamma)
\end{aligned}
$$

and

$C=\left(S_{\mathrm{N}} P\right)^{2}+S_{\mathrm{N}} P\left(\Lambda_{\mathrm{H}^{+}}+\Lambda_{\mathrm{HB}^{-}}\right)\left(K_{\mathrm{a} 1}^{2}+4 c_{\mathrm{E}} K_{\mathrm{a} 1}\right)^{1 / 2}$.

Here $C_{x}$ is the concentration of the analyte, $S$ denotes the signal of the conductivity detector, $\Lambda$ the specific conductivity of all involved species, $\mathrm{H}^{+}, \mathrm{HC}$ is $\mathrm{HCO}_{3}^{-}, C_{x}$ is the analyte, $K_{\mathrm{a} 1}$ is the first step dissociation constant of carbonic acid, $P$ is the cell constant of the conductivity detector and $C$ is the eluant concentration.

With the erratum that Eq. (17) in [12] is an error, and should read as given above.

Using this correction for non-linearity, the response of the IC system is linear between $20 \mu \mathrm{g}$ and $40 \mathrm{mgl}^{-1}$, spanning more than 3 decades. The detection limit is about $20 \mu \mathrm{g}$ in the watery phase (about $20-50 \mathrm{ng} \mathrm{m}^{-3}$ in ambient air). An accuracy of $5-10 \%$ is obtained by the IC detector, depending on the measured concentration (Table 1).

The total system looks quite complicated but has been proven now to be able to function totally automatically

Table 1

Accuracy of IC detector using a single-point calibration by bromide internal standard ( $R$ : real concentration $(\mathrm{ppm})$; S.D.: standard deviation)

\begin{tabular}{llllll}
\hline $\begin{array}{l}\text { Standard } \\
(\mathrm{ppm})\end{array}$ & $\mathrm{NO}_{3}^{-}$ & & & $\mathrm{SO}_{4}^{2-}$ & \\
\cline { 2 - 3 } \cline { 5 - 6 } & Measured & S.D. $/ R$ & & Measured & S.D. $/ R$ \\
\hline 0.1 & 0.102 & 0.015 & & 0.0100 & 0.024 \\
0.2 & 0.196 & 0.032 & & 0.186 & 0.031 \\
0.5 & 0.525 & 0.018 & & 0.468 & 0.011 \\
1 & 1.065 & 0.021 & & 0.94 & 0.023 \\
10 & 9.612 & 0.018 & & 9.58 & 0.018 \\
\hline
\end{tabular}

in field campaigns in The Netherlands, South Portugal, the US (Atlanta Super Site Experiment), only requiring standard maintenance such as replacing of solutions, etc. In Fig. 6 the results of monitoring of hourly nitrate, sulfate and ammonium concentrations at the site of ECN are given. These results indicate that two types of aerosols are present at this location: In conditions of westerly winds, sea salt aerosol is encountered which contains nitrate and sulfate but no ammonium, in accordance with earlier observations and the concentrations are very low (see e.g. period 31-10 to 3-11 and 6-11 to 9-11). During periods with southern and eastern winds (period 29-10 to 31-10 and 4-11 to 6-11) aerosol with a continental origin is encountered, very often nearly stoichiometric ammonium nitrate and ammonium sulfate. Ammonium nitrate is the dominant compound in this part of Western Europe, with clearly higher concentrations than ammonium sulfate. The observation of these two types of aerosols is important for the interpretation of the results of intercomparison with thermo-denuder systems as will be explained below.

\section{Description of techniques used in intercomparison experiments}

\subsection{ECN denuder filterpack combination (Keuken, 1989)}

The denuder/filter pack combination consists of sodium fluoride and phosphoric acid-coated denuders to capture nitric acid and ammonia. The filter pack consists of a Teflon (Mitex) filter, followed by two paper filters (Whatman 41) impregnated with sodium fluoride and phosphoric acid. The sum of the nitrate on the Teflon plus sodium fluoride filter gives the total of particulate nitrate (the sodium fluoride filter retains all nitric acid due to dissociation of ammonium nitrate) the sum of the Teflon filter plus phosphoric acid-coated filter gives ammonium. This procedure is very reliable, but quite time consuming and blanks are a problem.

3.2. ECN thermo-denuder system (Klockow et al., 1989; Keuken et al., 1989; Brink et al., 1996)

The thermo-denuder system for nitrate consists of a denuder, coated with magnesium sulfate. The first half of the denuder is sampled at room temperature and here nitric acid is absorbed by the magnesium sulfate coating. The second half is thermostated at $140^{\circ} \mathrm{C}$ and at this temperature ammonium nitrate (but not sodium or calcium nitrate) dissociates and the produced nitric acid is retained on the coating. After a sampling period of $30 \mathrm{~min}$, the separate sections of the denuder are heated to $700^{\circ} \mathrm{C}$; the nitrate is converted to $\mathrm{NO}_{x}$ and measured by a standard $\mathrm{NO}_{x}$ monitor. 


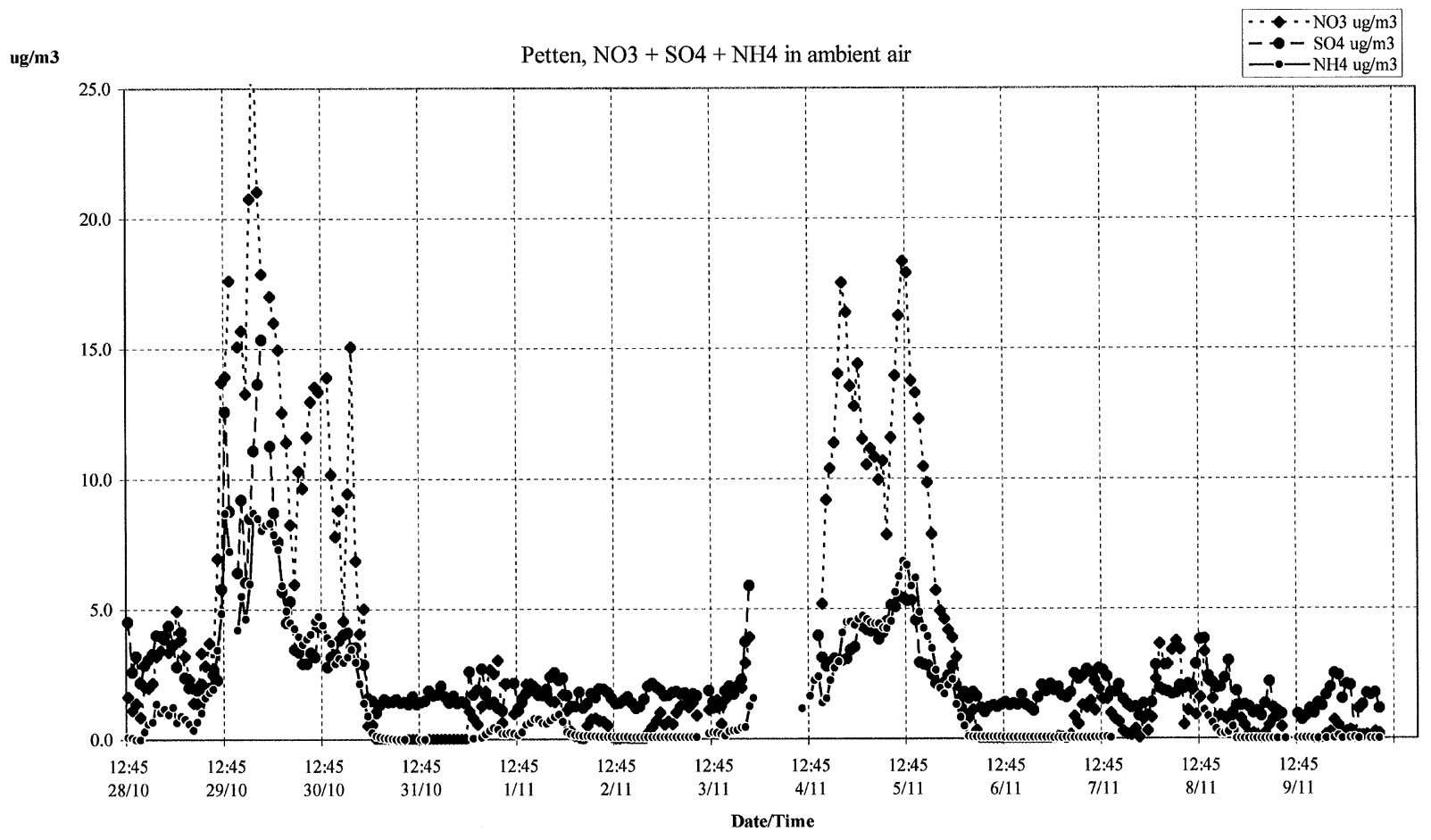

Fig. 6. Hourly measurements of nitrate, sulfate and ammonium at the ECN site.

The results of the thermo-denuders cannot be directly compared to the data obtained by the SJAC as thermo-denuder systems only sample the thermo-labile ( = ammonium nitrate) part of the aerosol, while SJAC (but also filterpack systems) measure the total amount of species in aerosols.

\subsection{Instrumentation used in the AEROBAL intercomparison}

Two "denuder difference" instruments were used. One consists of an active coal denuder to remove nitric acid and ammonia, followed by a Whatman paper filter. The amount of ammonium and nitrate sampled on the filter is used to calculate the amount of ammonium and nitrate in the aerosol. The other measures the concentration of nitric acid and ammonia by means of citric acid and sodium chloride-coated denuders. The total of particulate and gaseous nitrate and nitric acid as well as ammonia and ammonium is sampled by means of a filterpack, consisting of a Teflon, a nylon and a phosphoric acid-impregnated filter. The difference of total nitrate and ammonium found in the filterpack minus the amount found in the denuders is calculated to give the amount of ammonium and nitrate in the aerosols. Single quartz fiber filters, cellulose acetate and cellulose filters have also been used.

\subsection{The GIT/BNL aerosol sampler as developed by Rodney Weber}

The GIT/BNL particle-into-liquid collection system is similar to the SJAC. Steam is rapidly mixed with ambient sample air stripped of interfering gases, to produce a supersaturated vapor which activates all particles larger than roughly $50 \mathrm{~nm}$ diameter. These particles ultimately grow to $3-5 \mu \mathrm{m}$ diameter. Instead of a cyclone, in this case an impactor is used to capture the droplets. The impacted droplets are continually washed off with a purifed water flow of $0.1 \mathrm{ml} \mathrm{min}$. The resulting liquid stream is collected, air removed with a debubbler, and split for an analysis by a dual-channel ion chromatoraph. For the Atlanta study, measurements were repeated at 7-min intervals and each measurement consisted of a 4.3 min integrated sample.

\section{Validation of the SJAC and intercomparison with other methods}

Extensive intercomparisons between SJAC and other methods (as employed at ECN) were carried out in the field as well as in the laboratory. Intercomparison experiments, using the SJAC, the ECN filterpack system and thermo-denuder systems, were carried in a small 


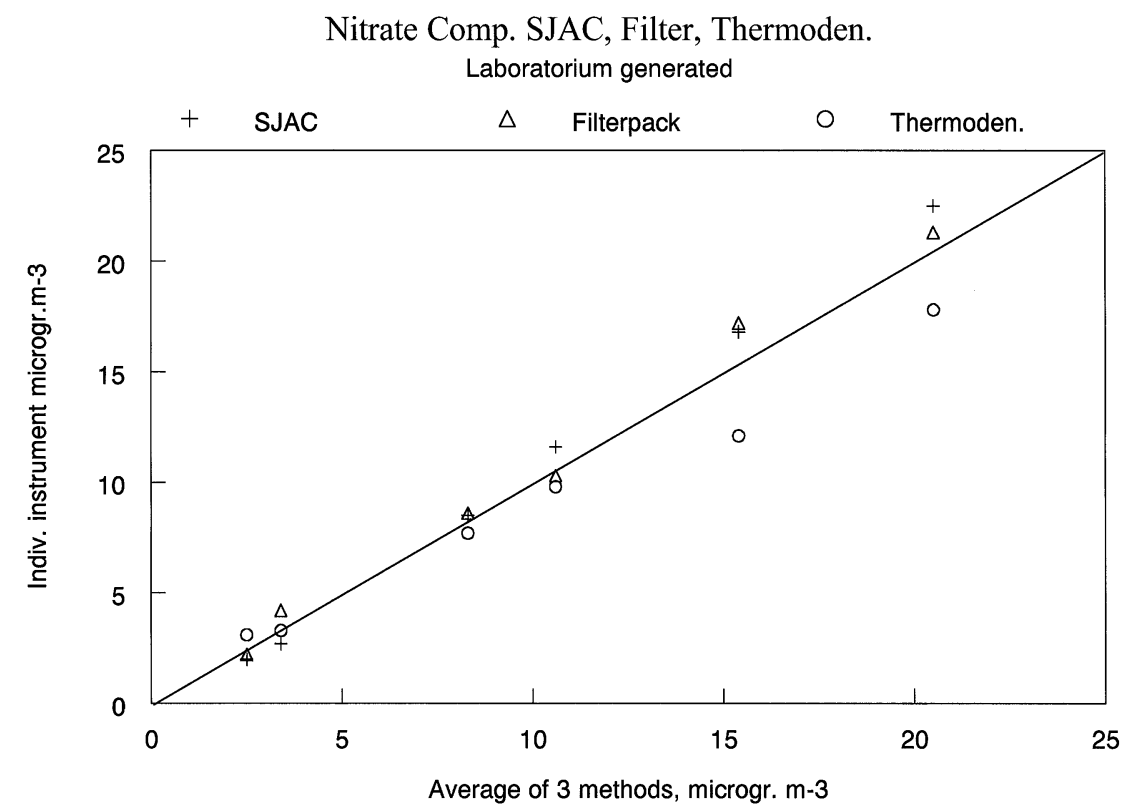

Fig. 7. Intercomparison of filterpacks, SJAC and thermo-denuder of aerosol generated in Mini-CHIEF.

cloud chamber (called mini-chief) which also can be used to generate aerosol mixtures of different composition and concentrations. The conditions are chosen in such a way that the ammonium nitrate concentration is constant during each run, is stable and in equilibrium with nitric acid and ammonia. Under these conditions, good results can be expected from filterpack measurements: If the sampling periods are short and equilibrium between nitric acid, ammonia and ammonium nitrate is established, no losses are observed of ammonium nitrate on the first, Teflon filter. The test aerosol consisted of ammonium nitrate and ammonium sulfate only, so only thermolabile compounds were present. Under these conditions thermo-denuder systems should sample $100 \%$ of the available nitrate, sulfate and ammonium. The results are given in Fig. 7.

The agreement between SJAC and filterpacks is indeed very good, we observe differences in the order of a few percent, at levels of $7 \mathrm{mg} \mathrm{m}^{-3}$ or higher. The results indicate that a random error of about $10 \%$ is observed between filterpacks and SJAC, with a slope of 1.1 and $R^{2}=0.98$. The agreement with thermo-denuder systems is also fine especially if one keeps in mind that thermodenuder systems tend to lose some nitrate generated by dissociation of ammonium nitrate, at concentrations of $15 \mu \mathrm{g}$ ammonium nitrate or higher.

A large intercomparison experiment was performed in the cadre of AEROBAL (an Eurotrac project) at ECN in the big CHIEF cloud chamber. Different mixtures of ammonium nitrate, ammonium sulfate and ammonia and nitric acid were generated and analyzed by denuder difference systems. Sodium nitrate aerosol was also generated to test, recovery, sampling and analytical efficiency. Elevated concentrations of precursors, nitric acid and ammonia as well as nitrous acid were used to test the methods for possible interferences.

The results confirm the conclusions of the earlier literature and the general European expertise on the behavior of filters. If extra $\mathrm{HNO}_{3}$ is generated, cellulose and acetate filters retain all nitrate, regardless of whether it originates from nitric acid or ammonium nitrate. Ammonia and ammonium are completely retained by acetate and cellulose filters, again leading to possible artifacts regarding the speciation of $\mathrm{NH}_{x}$ compounds. Teflon filters do not retain any nitric acid or ammonia, but here the opposite problem is encountered, ammonium nitrate is lost by evaporation, dissociation of ammonium nitrate producing ammonia and nitric acid. Denuder difference systems some times show large uncertainties, due to blank problems as well as high precursor concentrations, but give results in the right order of magnitude. The same picture is seen of nitric acid which is sampled. Nitrous acid does not interfere in any of the methods. An extensive description of the experiment including detailed results will appear elsewhere. The same conclusions must be drawn if ambient measurements are evaluated. Ammonium nitrate is lost from Teflon filters, cellulose and acetate filters retain gaseous nitric acid and ammonia.

During ACE 2 experiments, the ambient concentration of nitrate in aerosol in South Portugal was measured 
interc. SJAC-Impactor for amb. nitrate in microgr./m3

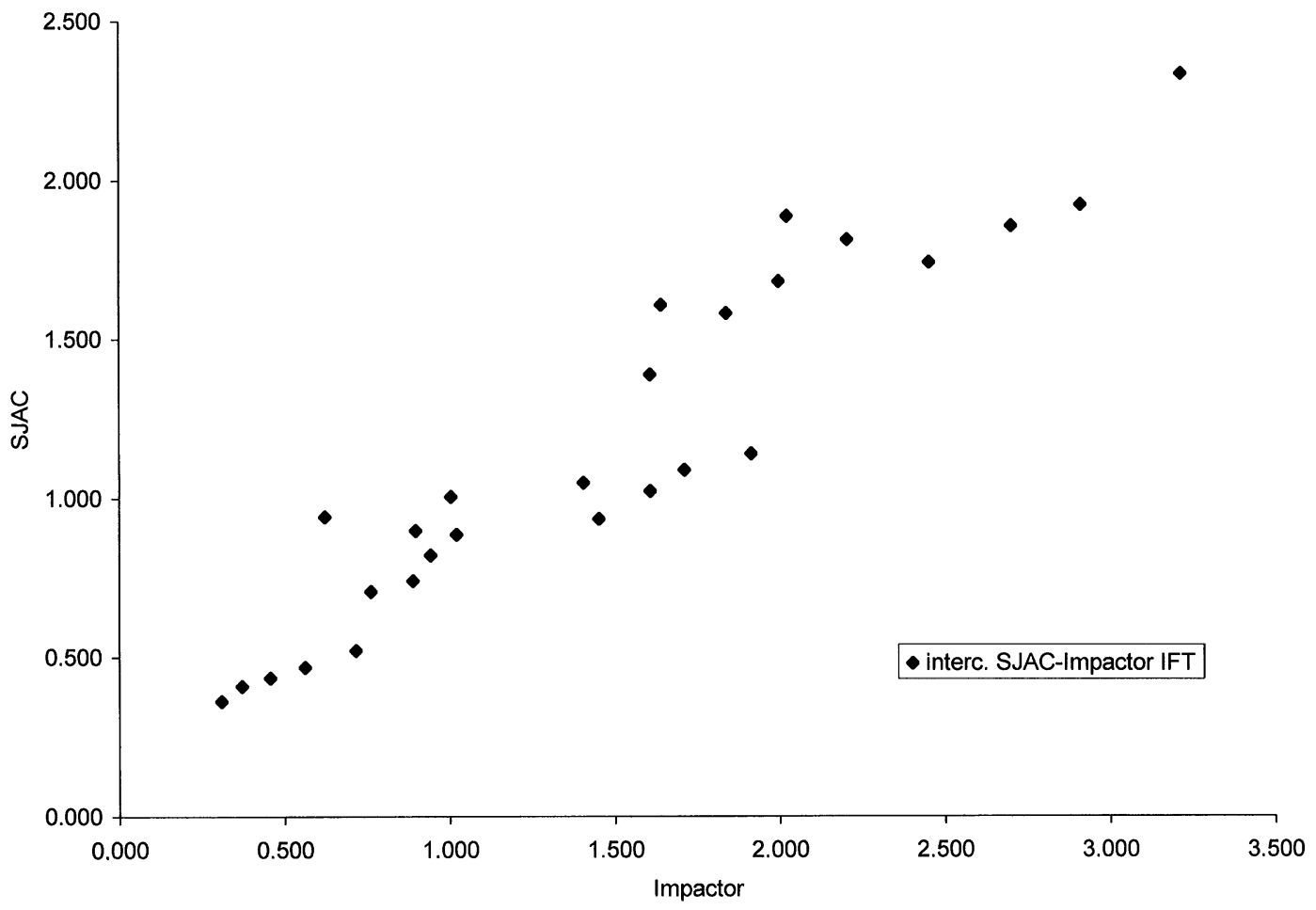

Fig. 8. Intercomparison for nitrate in ambient air between IFT-impactor and SJAC.

using both the SJAC (ECN) and impactors ( IFT, Leipzig, Neusuess et al., 2000). The results are given in Fig. 8.

The agreement of the results is quite satisfactory. It is remarkable though that in this case the impactor indicates higher concentrations than the SJAC. The sampling time for the impactor was quite short, less than $3 \mathrm{~h}$. At very short sampling times the loss of ammonium nitrate is generally not a problem, at longer sampling times as usually applied, these losses can be large. The reason for the difference is that aerosol near the seashore was sampled, which contained nitrate on large sea salt particles. The inlet of the SJAC was not optimized for larger particles, while the impactor sampled them quite efficiently. $R^{2}$ is 0.9 , the slope is about 0.65 and from this slope and the size distribution as measured by the impactor, one can deduce that the SJAC with this inlet system (simple Teflon tube) samples particles up to $4 \mu \mathrm{m}$ diameter.

Extensive intercomparison experiments between SJAC and thermo-denuders were performed at the site of ECN at Petten in The Netherlands, see Fig. 9. An episode of rather high ammonium and nitrate concentrations was chosen. During this episode easterly winds prevailed and generally continental aerosol, containing little sodium nitrate but mainly ammonium nitrate, was present. During westerly winds the thermo-denuder detects very little

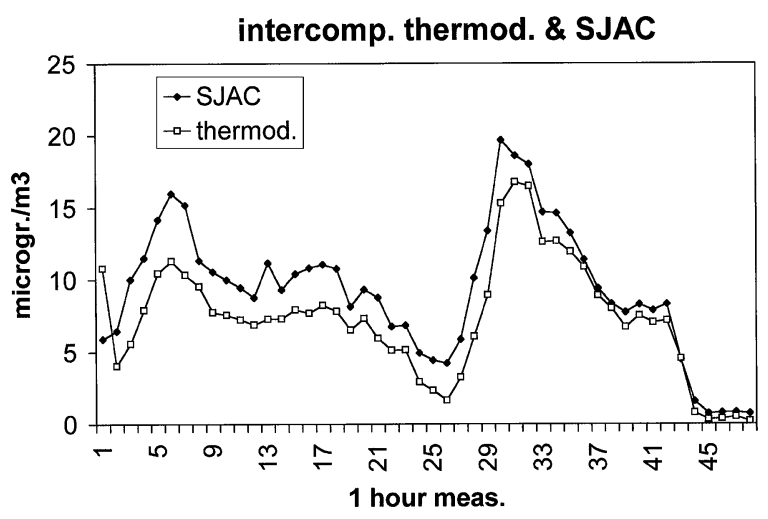

Fig. 9. Intercomparison of SJAC and thermo-denuder for ambient nitrate.

nitrate as most of the nitrate in aerosol is present in the form of sodium nitrate, due to the interaction of sodium chloride with nitric acid. The correlation $\left(R^{2}=0.93\right)$ is clearly very high. The thermo denuder gives lower results (slope 0.84 ) and an offset of $0.7 \mu \mathrm{g} \mathrm{m}^{-3}$, which are both caused by the presence of sodium nitrate in sea salt which is not thermo-labile. The SJAC, samples all aerosol including sodium nitrate, while the thermo denuder system does not sample these stable nitrates. 
Intercomparison ammonium and nitrate filter pack in microgram per $\mathrm{m} 3$

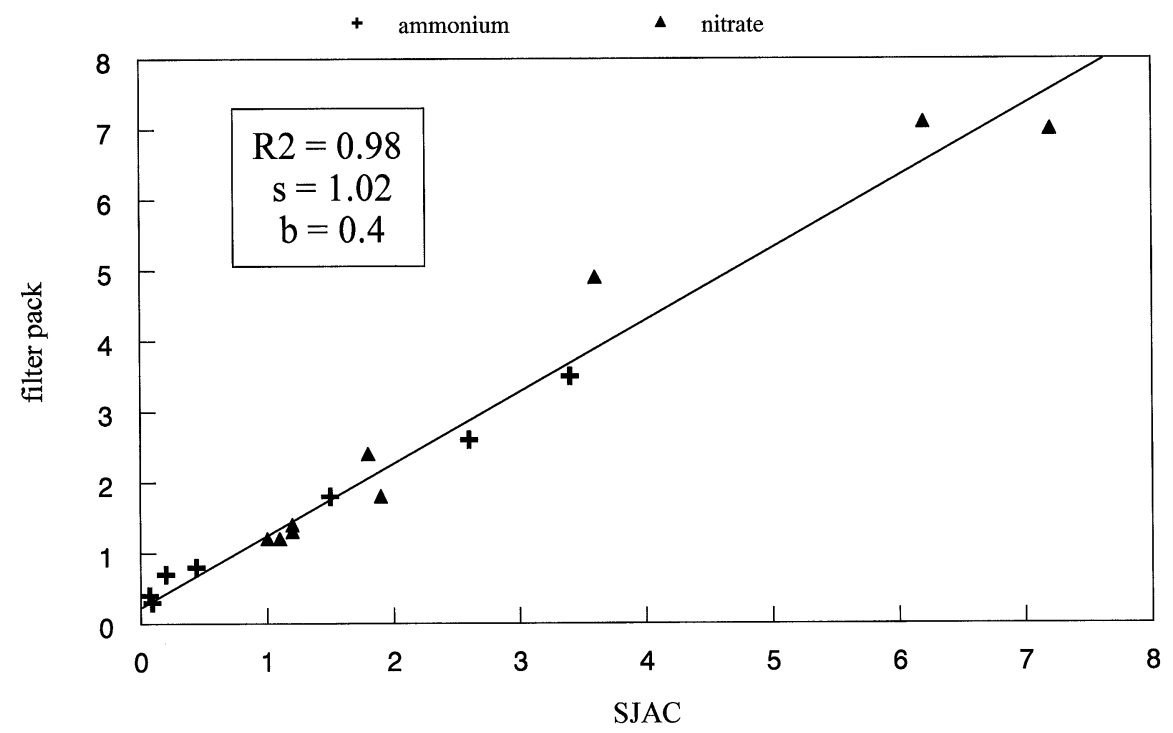

Fig. 10. Intercomparison of SJAC and filterpack for ambient nitrate and ammonium.

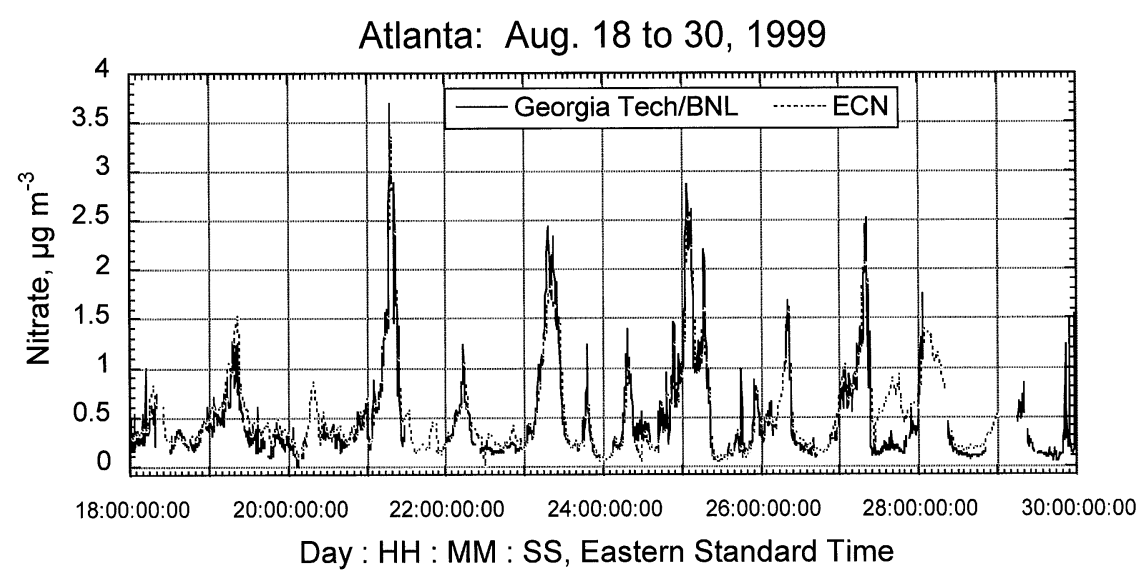

Fig. 11. Intercomparion of SJAC and NBL/GIT apparatus in Atlanta, Supersite.

A last series of intercomparison between denuder filterpack combinations and the SJAC was performed in early January 2000 and the results for nitrate and ammonium are given in Figs. 10 and 11. The correlation coefficients are 0.99 and 0.98 , intercepts are 0.4 and 0.2 and the slopes are 0.91 and 1.04, respectively, for ammonium and nitrate. These values of the intercepts again indicate the problems with blanks as well as detection limits for the denuder filter pack combination. During the Supersite Experiment at Atlanta, many methodologies have been used and the results of this large scale intercomparison experiment will be published elsewhere.
Two continuous methods, SJAC and the NBL/Georgia Tech method as developed by Weber have been compared in Fig. 11. While one can argue that the methods are quite similar, based both on droplet formation around aerosol and followed by IC detection, it should be pointed out that the mechanism of drop formation as well as calibration of the IC system are quite different. The agreement is very good indeed and again a proof that reliable on-line measurements are indeed feasible with this instrumentation. A more extensive treatment of the results of this intercomparison experiment will be published elsewhere. 


\section{Conclusions}

The SJAC has proved to be a reliable instrument, which indeed can be used in field campaigns to provide in situ and real-time data regarding the composition of aerosols. The combination of the Steam Jet Aerosol Sampler with on-line detection devices such as the ammonium conductivity detector and an IC system with 1-point internal standard calibration and suppression correction is a powerful tool for the study of the chemical composition of aerosols. The total apparatus has proved to be sturdy and reliable, even if it may look complicated. It has been used in the laboratory as well as different field campaigns in Europe and the US and can be transported relatively easy. The instrument has been validated extensively in the laboratory as well as in intercomparison experiments. The results show that the method indeed gives reliable results under a wide range of conditions. The detection limits of the apparatus, in the order of $0.02 \mu \mathrm{g}$ of ammonium and nitrate per $\mathrm{m}^{3}$ make it suitable for use in background areas. The time resolution of $15 \mathrm{~min}$ to $2 \mathrm{~h}$ is sufficient for the study of the role of aerosols in different environmental problems such as the radiative forcing by aerosols, the impact of aerosols on visibility and the effect of aerosols on human health.

\section{Acknowledgements}

We are indebted to Herrn Dr. Christian Neusüß and Dr. Rodney Weber for the use of, respectively, the Sagres and the Atlanta data.

\section{References}

Bergin, M.H., Ogren, J.A., Schwartz, S.E., McInnnes, L.M., 1997. Evaporation of ammonium nitrate in a heated nephelometer; implications for field measurements. Environmental Science and Technology 31, 2878-2883.

Brink, H.M. ten, Veefkinf, J.P., Waijers-Ijpelaan, van der, Hage, J.C., 1996. Aerosol light scattering in The Netherlands. Atmospheric Environment 30, 4251-4261.

Carlson, R.M., Cabrera, R.I., Paul, J.L., Quick, J., Evans, R.Y., 1990. Rapid direct determination of ammonium and nitrate in soil and plant tissue extracts. Communications in Soil Science and Plant Analysis 21 (13-16), 1519-1529.

Charlson, R.J., Schwartz, S.E., Hales, J.M., Cess, R.D., Coakley Jr., J.A., Hansen, J.E., Hoffmann, D.J., 1992. Climate forcing by anthropogenic aerosols. Science V255, 423-430.

Chow, J., 1995. Critical review of measurement methods to determine compliance with ambient air quality standards for suspended particulates. Journal of Air and Waste Management Association 45, 320-382 (and references therein).

Herring, S., Cass, G., 1999. The magnitude of bias in the measurement of PM-2.5 arising from volitalization of particulate nitrate from teflon filters. Journal of Air and Waste Management Association 49, 725-733.

IPCC, 1998. The regional impacts of climatic change. In: Watson, R.T., Zinyowera, M.C., Moss, R.H. (Eds.), Intergovernmental Panel on Climatic Change. Cambridge University Press, Cambridge, 1998.

Keuken, M.P., 1989. The determination of acid-deposition related compounds in the lower atmosphere. Thesis, University of Utrecht.

Keuken, M.P., Wayers-Ypelaan, A., Mols, J.J., Otjes, R.P., Slanina, J., 1989. The determination of ammonia in ambient air by an automated thermo-denuder system. Atmospheric Environment 23, 2177-2185.

Khlystov, A., Wyers, G.P., Slanina, J., 1995. The steam-jet aerosol collector. Atmospheric Environment 29 (17), 2229-2234.

Klockow, D., Niessner, R., Malejczyk, M., Kiendl, H., vom Berg, B., Keuken, M.P., Wayers-Ypelaan, A., Slanina, J., 1989. Determination of nitric acid and ammonium nitrate by means of a computer-controlled thermo-denuder system. Atmospheric Environment 23, 1131-1138.

Niessner, R., Klockow, D., 1980. A thermoanalytical approach to speciation of atmospheric strong acids. International Journal of Environmental Analytical Chemistry 8, 13-175.

Neusuess, C., Weise, D., Birmili, W., Wex, H., Wiedensohler, A., Covert, D.S., 2000. Size-segregated chemical, gravimetric and number distribution-derived mass closure of the aerosol in Sagres, Portugal during ACE-2. Tellus 52B, 169-184.

Oms, M.T., Jongejan, P.A.C., Veltkamp, A.C., Wyers, G.P., Slanina, J., 1996. Continuous monitoring of atmospheric $\mathrm{HC}_{1}, \mathrm{HNO}_{3}, \mathrm{HNO}_{2}$ and $\mathrm{SO}_{2}$ by wet-annular denuder sampling with on-line chromatographic analysis. International Journal of Analytical Chemistry 2, 207-218.

Os, M.J.van, Slanina, J., de Ligny, C.L., Agterdenbos, J., 1984. Linear calibration in ion chromatography by calculating total amount of sample from measured conductivity data. Analytica Acta 156, 169-180.

Simon, P.K., Dasgupta, P., 1995. Continuous automated measurement of gaseous nitric and nitrous acids and particulate nitrite and nitrate. Environmental Science and Technology $29,1534-1541$.

Slanina, J., de Wild, P.J., Wyers, G.P., 1992. The application of denuder systems to the analysis of atmospheric components. In: Nriagu, J.O. (Ed.), Gaseous Pollutants, Characterization and Cycling. Wiley, New York, pp. 129-154.

Slanina, J., Wyers, G.P., 1994. Monitoring of atmospheric components by automatic denuder systems. Fresenius Journal of Analytical Chemistry 350, 47-473.

Wyers, G.P., Otjes, R.P., Waayers, A., Mols, J.J., Khlystov, A., Arends, B.G., Jongejan, P.A.C., 1992. Development of instrumentation for dry deposition measurements. In: Slanina, J. (Ed.), BIATEX Annual Report 1991. Published by the ISS, Fraunhofer Institut, BRD and the Commission of the European Communities.

Wyers, G.P., Otjes, R.P., Slanina, J., 1993. A continuous-flow denuder system for the measurement of ambient concentrations and surface-exchange fluxes of ammonia. Atmospheric Environment 27, 2085-2209.

Zellweger, C.M., Ammann, A., Hofer, P., Baltensperger, U., 1999. $\mathrm{NO}_{y}$ speciation with a combined wet effluent diffusion denuder-aerosol collector coupled to ion chromatography. Atmospheric Enviroment 33, 1131-1140. 